\title{
Design Science, Engineering Science and Requirements Engineering
}

\author{
Roel Wieringa \\ Department of Computer Science \\ University of Twente, The Netherlands \\ roelw@cs.utwente.nl
}

\author{
Hans Heerkens \\ School of Management and Governance \\ University of Twente, The Netherlands \\ j.m.g.heerkens@utwente.nl
}

\begin{abstract}
For several decades there has been a debate in the computing sciences about the relative roles of design and empirical research, and about the contribution of design and research methodology to the relevance of research results. In this minitutorial we review this debate and compare it with evidence about the relation between design and research in the history of science and technology. Our review shows that research and design are separate but concurrent activities, and that relevance of research results depends on problem setting rather than on rigorous methods. We argue that rigorous scientific methods separate design from research, and we give simple model for how to do this in a problem-driven way.
\end{abstract}

\section{The Design Science Debate in the Comput- ing Sciences}

In several computing sciences there is an ongoing debate about the relationship between research and design. In software engineering (SE), the use of empirical methods, in particular experimental ones, started in the 1980s [1], but it remained a separate approach called "empirical software engineering", next to the design-oriented approach that is traditional in SE. In the 1990s several authors pointed out that the relevance of designs would be increased by the use of empirical research to validate the designs $[11,20]$. In addition, empirical studies of the methodological structure of software engineering papers confirmed that validation lacked in many cases [42, 47, 15]. Subsequently, papers were published about how to do empirical research in SE $[19,34]$. This is picked up slowly by the community [40].

In information systems (IS), the design-versus-research debate started in a similar way but it has led to an almost diametrically opposing point of view. In the 1980s, a large number of IS researchers called for more rigor, meaning more empirical research methods and less unvalidated design proposals $[13,29,32]$. This has led to the introduc- tion of rigorous research methods in IS, but towards the end of the 1990s, several researchers complained about the lack of relevance of empirical results [4, 43]. Some IS researchers argued that the investigation of artifacts designed by the researcher herself could be a source of knowledge too [27, 33], and Hevner et al. [17] claimed that research relevance would be the result of including design as a research method. They proposed to mix design and research, calling the resulting method "design science", with reference to Simon [39].

The proposal to do "design science" is not the only response to the complaint about lack of relevance in IS research: The use of case study and action research methods has been another response $[2,3,10,24,26]$. These methods take more of the context of the subject of study into account than is possible (or desirable) in laboratory research. We will turn to context-rich research methods later. Here we point out a property of some forms of case study research and of all forms of action research: These research approaches involves some form of interaction of the research with the subject of study. And in action research, we find the claim that the attempt to change the subject of research increases the relevance of research even though, as some of the proponents of this research say, this decreases the methodological rigor of this research.

Comparing the discussions in SE and IS, we observe that the attempts to increase relevance in these two disciplines are mirror images of each other: IS complains about lack of relevance of results produced by rigorous empirical methods, and attempts to increase relevance by allowing design or intervention to be part of rigorous research method, and SE complains about lack of relevance of design results and attempts to increase relevance by promoting rigorous empirical research methods. Apparently, design and empirical research separately do not guarantee relevance. But would they perhaps jointly guarantee relevance? And if they are combined, how to do this in a methodologically sound way? To discuss this question we analyze the relationship between research and design in the history of science and technology. 


\section{Evidence from the History of Science and Technology}

The relation between research and design is still widely viewed to be linear, meaning that scientific research produces true propositions that are then, so it is believed, converted into useful artifacts by engineers. Therefore, in this view, technology is applied science [6]. This view is generally traced to an influential report by Vanevar Bush published just after World War II [7], but its roots can be found in the 19th century, when scientists wanted to secure continued funding by pointing out the potentially great practical benefits of curiosity-driven research, and engineers wanted to acquire a higher status by associating themselves with scientific research [21].

However, research in the history of technology has shown the linear model to be false [18, 30, 46]. People have developed technology as long as they exist, and did so mostly without the input of science. Rather, in the 17th century, instrument makers provided the technology, such as barometers, thermometers, and telescopes, by which scientists, such as astronomers, could make observations [5, 44]. In the 18th century, engineers started to investigate the properties of artifacts, such as waterwheels, steam machines and porcelain ovens using what we now call the scientific method [25, 28, 31]. By the end of the 19th century, engineering research was established in industrial laboratories and technical universities [5]. Even in the 20th century it is hard to find technical innovations that were driven by basic scientific research; the more common pattern is that engineers design and construct artifacts using available knowledge, and that scientists investigate why artifacts constructed earlier by engineers actually work $[18,30,46]$.

From these and other historical cases it turns out that technology and science are two separate, concurrent activities in which artifacts flow one way and knowledge flows the other way. We call this the concurrent model [22]. In this model, engineers may design instruments to be used in research, and researchers may investigate artifacts, which results in knowledge that may be used by engineers. Transfers in either direction may be push or pull, i.e. initiated by the sender (engineer or scientist) or receiver (scientist or engineer). Cases of push from researchers to engineers are rare.

Despite its abundant falsification by historical evidence, belief in the linear model of transfer from basic science to applied science persists, partly because the categories of basic science, applied science and development are encoded into statistics that have been collected by the OECD for decades [16], and partly because it is politically expedient to distinguish basic from applied science [8].

\section{Rigor "Versus" Relevance}

Engineers select technical problems to solve, not because scientists have made available new knowledge, but because they perceive an actual or possible need in society. And researchers may select research problems out of intellectual curiosity, or because they want to produce useful knowledge, or both [41].

The historical evidence shows that relevance is a result of selecting relevant problems to solve. Therefore, relevance comes and goes, depending on the problems and goals stakeholders have at any point in time. For example, when crystal detectors were used in early radios as receivers, research into crystal structures was highly relevant. However, after crystal detectors were replaced by electron valve artifacts [14], research into crystal structures had become irrelevant. It was still performed in universities though, and when decades later radar was developed, it became relevant again. This laid the foundation for the invention of transistors after World War II.

The "dilemma" of rigor versus relevance was introduced by Schön, who seems to imply that technical science follows the linear model [37, pp. 26, 31] and then laments that applying this model to social problems leads to irrelevant results. If a rigorous research method would indeed mean following the linear model, then the historical evidence shows that rigorous methods in this sense hardly exist. However, we think that using a rigorous research method means, essentially, not claiming more than you can justify. This is operationalized in terms of such requirements as to describe research designs explicitly, to discuss threats to validity, to submit to peer reviews, and to require repeatability of experiments. But none of this implies nor excludes relevance. One can and must be as rigorous in answering relevant as in answering irrelevant research questions-given the available resources, such as time, people and money, and within applicable constraints, such as moral and legal norms and stakeholder goals.

\section{Conditions of Practice}

We define technical research as the investigation of the properties of artifacts. Technical researchers may interleave designing (and building) artifacts with investigating them, but they may also investigate the properties of artifacts designed or built by others. Are there specific research methods used in technical research but not in other sciences, such as social sciences or natural sciences? We have not found any difference based on subject matter. The method to investigate a particular research question must be justified by an analysis of that question, within the boundaries of available resources and applicable constraints. 
Historical studies do show one aspect in which engineering research differs from other kinds of research, although this is a gradual difference: Engineering research needs to incorporate conditions of practice, which are the numerous variables that exist in concrete artifacts and that can impact their behavior [23, 25]. The importance of conditions of practice forces the technical researcher to resort to approximate computational methods, and simulation and modeling to find answers, and it may require case studies and pilot projects to rather than laboratory experiments to test hypotheses. But none of this implies a difference in scientific research methods used in engineering science from those used in natural or social sciences.

\section{Conclusions}

(1) We conclude from our historical tour that the linear model is false and that a concurrent model is more accurate. The linear model however is widely believed in software engineering too $[36,38]$. However, closer inspection of some transfer models reveals that there is a terminological problem. What is often called "research" in industrial laboratories is actually engineering, i.e. the creation of useful artifacts, and "basic research" in an industrial context is often exploratory engineering, i.e. the creation of artifacts of which future utility is very uncertain [8, 35]. For example, the linear transfer model in pharmacy starts with exploratory development of new medicines [9]. In these models, design and research interact in a concurrent way, as explained earlier: Engineers develop artifacts that are investigated by researchers.

(2) Combining design and research is full of methodological pitfalls and must be done in a methodologically sound way [45]. In the concurrent model, design and research are two separate but interacting activities. Each has its own methodology, and each has its own evaluation criteria. Design results should be relevant for stakeholders' goals; research results should be valid. Researchers should not claim more than they can justify, and doing this, they should consider every possible way in which they could be wrong [12, page 341]. Methodologically rigorous research can produce relevant or irrelevant results, depending on the research context, in particular on the goals that stakeholders happen to have at the time.

(3) Technical research will eventually always have to deal with conditions of practice. This does increase relevance, provided that the research question is relevant to some stakeholder goal. This means that context-rich methods such as field research, case studies, simulation and modeling will be frequently used research methods in technical science. In these cases, rigorous research design-dealing with all relevant conditions of practice-produces relevant results, provided these conditions of practice are relevant for some stakeholder goal.

(4) Complicated models for "design science" such as produced by Nunamaker and Chen [33], March and Smith [27] and Hevner et al. [17] mix up design and research and therefore run the danger of producing unsound results; and to the extent that they ignore problem setting, they may produce irrelevant results to boot. We do not believe in rigidly prescriptive methodology but in problemdriven methodology: In answering a research question, the researcher should describe choices made in the research design explicitly, and justify them in terms of the research question. Similarly, in solving a technical design problem, the designer should describe her choices explicitly and justify them in terms of the problem, e.g. in terms of a problem diagnosis and of stakeholder goals.

(5) Our analysis leads to a goal-oriented view on RE. Requirements engineering is the activity to achieve a match between the properties of artifacts and the goals of stakeholders. Ensuring relevance of artifacts is therefore a responsibility of requirements engineers. RE researchers design techniques to be used by RE practitioners, and as designers they have the responsibility to design techniques relevant for RE practitioners. As researchers, they investigate techniques used by RE practitioners, whether the techniques were developed by themselves (the researchers) or by others. Therefore, as researchers, their responsibility is to use rigorous research methods in investigating these techniques; this is independent from any concern for relevance.

\section{References}

[1] V. Basili and D. Weiss. A methodology for collecting valid software engineering data. IEEE Transactions on Software Engineering, SE-10(6):728-738, November 1984.

[2] R. Baskerville. Distinguishing action research from participative case studies. Journal of Systems and Information Technology, 1(1):25-45, March 1997.

[3] I. Benbasat, D. Goldstein, and M. Mead. The case research strategy in studies of information systems. MIS Quarterly, 11(3):369-386, September 1987.

[4] I. Benbasat and R. Zmud. Empirical research in information systems: the practice of relevance. MIS Quarterly, 23(1):316, March 1999.

[5] Böhme, V. D. Daele, and W. Krohn. The 'scientification' of technology. In W. Krohn, E. Layton, and P. Weingart, editors, The Dynamics of Science and Technology. Sociology of the Sciences, II, pages 219-250. Reidel, 1978.

[6] M. Bunge. Technology as applied science. In F. Rapp, editor, Contributions to the Philosophy of Technology, pages 19-39. Reidel, 1974.

[7] V. Bush. Science, the endless frontier. Technical report, Office of Scientific Research and Development, 1945. http://www.nsf.gov/about/history/vbush1945.htm.

[8] J. Calvert. What's so special about basic research? Science, Technology and Human Values, 31(2):199-220, March 2006. 
[9] A. Davis and A. Hickey. A new paradigm for planning and evaluating requirements engineering research. In 2 nd International Workshop on Comparative Evaluation in Requirements Engineeering, pages 7-16, 2004.

[10] K. Eisenhardt. Building theories from case study research. The Academy of Management Review, 14(4):532-550, October 1989.

[11] N. Fenton, S. Pfleeger, and R. Glass. Science and substance: A challenge to software engineers. IEEE Software, 11(4):86-95, July 1994.

[12] R. Feynman. Surely You're Joking Mr. Feynman! Vintage, 1992.

[13] R. Galliers. Choosing information system research approaches. In R. Galliers, editor, Information Systems Research: Issues, Methods and Practical Guidelines, pages 144-166. Blackwell, 1992.

[14] M. Gibbons and C. Johnson. Science, technology and the development of the transistor. In B. Barnes and D. Edge, editors, Science in Context. Readings in the Sociology of Science, pages 177-185. Open University Press, 1982.

[15] R. Glass, V. Ramesh, and I. Vessey. An analysis of research in the computing disciplines. Communications of the ACM, 47(6):89-94, June 2004.

[16] B. Godin. The linear model of innovation: The historical reconstruction of an analytic framework. Science, Technology and Human Values, 31(6):639-667, November 2006.

[17] A. Hevner, S. March, P. J, and S. Ram. Design science in information system research. MIS Quarterly, 28(1):75-105, March 2004

[18] A. Keller. Has science created technology? Minerva, 22(2):160-182, June 1984.

[19] B. Kitchenham, S. Pfleeger, D. Hoaglin, K. Emam, and J. Rosenberg. Preliminary guidelines for empirical research in software engineering. IEEE Transactions on Software Engineering, 28(8):721-733, August 2002.

[20] B. Kitchenham, L. Pickard, and S. Pfleeger. Case studies for method and tool evaluation. IEEE Software, 12(4):52-62, July 1995.

[21] R. Kline. Construing "technology" as "applied science": Public rethoric of scientists and engineers in the United States, 1880 - 1945. Isis, 86(2):194-221, 1995.

[22] S. Kline. Innovation is not a linear process. Research Management, 24(4):36-45, July/August 1985.

[23] G. Küppers. On the relation between technology and science - goals of knowledge and dynamics of theories. The example of combustion technology, thermodynamics and fluid dynamics. In W. Krohn, E. Layton, and P. Weingart, editors, The Dynamics of Science and Technology. Sociology of the Sciences, II, pages 113-133. Reidel, 1978.

[24] F. Lau. A review on the use of action research in information systems studies. In A. Lee, J. Liebenau, and J. DeGross, editors, Information Systems and Qualitative Research, pages 31-68. Chapman \& Hall, 1997.

[25] E. Layton. Mirror-image twins: The communities of science and technology in 19th century America. Technology and Culture, 12(4):562-580, October 1971.

[26] A. Lee. A scientific methodology for MIS case studies. MIS Quarterly, 13(1):33-50, March 1989.
[27] A. March and G. Smith. Design and natural science research on information technology. Decision Support Systems, 15(4):251-266, December 1995.

[28] B. Marsden. Watt's Perfect Engine. Steam and the Age of Invention. Icon Books, 2002.

[29] F. McFarlan, editor. The Information Systems Research Challenge. Harvard Business School Press, 1984.

[30] J. McKelvey. Science and technology: The driven and the driver. Technology Review, pages 38-47, January 1985.

[31] N. McKendrick. The role of science in the industrial revolution: A study of Josiah Wedgwood as a scientist and industrial chemist. In M. Teich and R. Young, editors, Changing Perspectives in the History of Science, pages 274-319. Heinemann, 1973.

[32] E. Mumford, R. Hirschheim, and A. Wood-Harper, editors. Research Methods in Information Systems. Elsevier NorthHolland, 1985.

[33] J. Nunamaker, M. Chen, and T. Purdin. Systems development in information systems research. Journal of Management Information Systems, 7(3):89-106, Winter 1990-1991.

[34] S. Pfleeger. Experimental design and analysis in software engineering. Annals of Software Engineering, 1(1):219-253, 1995.

[35] S. Pfleeger. Understanding and improving technology transfer in software engineering. Journal of Systems and Software, 47(2-3):111-124, July 1999.

[36] S. Redwine and W. Riddle. Software technology maturation. In Proceedings of the 8th International Conference on Software Engineering (ICSE 85), pages 189-199. IEEE Computer Science Press, 1985.

[37] D. Schön. The Reflective Practitioner: How Professionals Think in Action. Arena, 1983.

[38] M. Shaw. Prospects for an engineering discipline of software. IEEE Software, 7(2):15-24, November 1990.

[39] H. Simon. The Sciences of the Artificial. The MIT Press, 1981. Second edition.

[40] D. Sjøberg, J. Hannay, O. Hansen, V. Kampenes, A. Karahasanović, N.-K. Liiborg, and A. Rekdal. A survey of controlled experiments in software engineering. IEEE Transactions on Software Engineering, 31(9):733-753, September 2005.

[41] D. Stokes. Pasteur's quadrant: Basic science and technological innovation. Brookings Institution Press, 1997.

[42] W. Tichy. Should computer scientists experiment more? Computer, 31(5):32-40, May 1998.

[43] R. Weber. The problem of the problem. MIS Quarterly, 27(1):iii-ix, March 2003.

[44] R. Westfall. The construction of modern science: Mechanisms and Mechanics. Cambridge University Press, 1977, 2005. First printing Wiley, 1971.

[45] R. Wieringa and J. Heerkens. The methodological soundness of requirements engineering papers: A conceptual framework and two case studies. Requirements Engineering Journal, 11(4):295-307, 2006.

[46] G. Wise. Science and technology. Osiris (2nd Series), 1:229-246, 1985.

[47] M. Zelkowitz and D. Wallace. Experimental validation in software engineering. Information and Software Technology, 39:735-743, 1997. 